\title{
Lectura, escritura y oralidad: la narración colectiva de Colombia en tiempos de posconflicto
}

Reading, Writing, and Oral Speech: Collective Narration in Colombia in the age of Post-Conflict

Natalia Montejo Vélez* Corporación Universitaria Minuto de Dios, Bogotá, Colombia https://orcid.org/0000-0001-7765-0480

Federico López**

Universidad de la Salle, Bogotá, Colombia https://orcid.org/0000-0002-7162-9784

Artículo de investigación

Fecha de recepción: 16 de septiembre de 2019

Fecha de aceptación: 29 de octubre de 2019

\section{Para citar este artículo}

Montejo Vélez, N. y López, F. (2020). Lectura, escritura y oralidad: la narración colectiva de Colombia en tiempos de postconflicto. Campos en Ciencias Sociales, 8(1), 231-257. Dor: https://doi.org/10.15332/25006681/5721

* Magíster en Filosofía de la Pontificia Universidad Javeriana. Correo electrónico: natalia.montejo@gmail. com

** Magíster en Filosofía de la Pontificia Universidad Javeriana. Correo electrónico: ficolopez1280@gmail. com 


\section{REsUMeN}

Este artículo trata sobre la relevancia de la lectura, la escritura y la oralidad en la Colombia del posconflicto. Para tal fin, tomamos categorías conceptuales como "comunidad letrada", "lectura crítica" e "imaginación moral", al igual que reflexiones teóricas y testimoniales sobre las prácticas narrativas en distintos contextos. Asimismo, desde la memoria histórica como concepto, pero a la vez como testimonio, planteamos los posibles desafíos que enfrenta el país al contar la historia de lo sucedido en tantos años de conflicto armado. De esta manera, abordamos varios productos literarios, visuales, cinematográficos y plásticos realizados en el país, que nos permitieron comprender que las prácticas narrativas pueden generar cambios simbólicos y culturales frente a fenómenos como la normalización de la violencia, la corrupción del lenguaje político, la instrumentalización de la democracia y las tensiones inherentes entre memoria y perdón; problemas latentes en los años de confrontación armada pero que ahora aparecen con más claridad en la Colombia del posconflicto.

Palabras clave: comunidad letrada, imaginación moral, memoria, narraciones, postconflicto.

\section{Abstract}

This article deals with the relevance of reading, writing, and oral speech in Colombia's post conflict age. To achieve this end, we take conceptual categories such as lettered communities, critical reading and moral imagination, as well as theoretical and testimonial reflections about narrative practices in different contexts. Likewise, based on historical memory as a conceptual category, but also as testimonial, we lay out the possible challenges that the country faces when telling the story about what happened in so many years of armed conflict. Thus we approach different literary, visual, cinematographic, and plastic products made in the country, which led us to understand that narratives focused in the post conflict can generate symbolic and cultural changes in the face of phenomena such as the normalization of violence, the corruption of political language, the instrumentalization of democracy and the inherent tensions between memory and forgiveness; all of which were latent problems in the years of armed confrontation but now appear more clearly in the Colombia's postconflict age.

Keywords: lettered communities, moral imagination, memory, narratives, post-conflict age. 


\section{LA APUESTA POR EL CAMBIO DE LA FUNDACIÓN ITINERARIOS DE LECTURA Y EsCRITURA (FILIE)}

En nuestro trabajo en la Fundación Itinerarios de Lectura y Escritura (FILIE) surgió la pregunta sobre el rol de la lectura, la escritura y la oralidad en una época de posconflicto como la que vivimos actualmente en el país. Sin duda, esta es una palabra que genera debate en vista de lo que ha sucedido en los últimos años, luego de la firma del acuerdo de paz entre el Estado y las Farc. En efecto, Colombia, lejos de superar viejos rencores políticos y sociales, insiste en volver a lo que hemos vivido en otros años: desaparición física del adversario ideológico, legitimación de una violencia justa y necesaria, persecución de la libertad de prensa, hostigamiento de las altas cortes cuya misión es cuidar el cumplimiento cabal de la Constitución de 1991, en fin. Más allá de la coyuntura nacional, las raíces del posconflicto no han desaparecido; al contrario, están en lo más profundo del inconsciente colombiano, un terreno fértil para miedos, odios y resentimientos. Sin embargo, así varios de los sectores más reaccionarios y anacrónicos pretendan regresarnos al pasado, lo cierto es que el país ha empezado a cambiar. Ahora bien, establecer si este cambio ha sido positivo o negativo es algo que excede el alcance de nuestro propósito, pero es posible proponer algunas posibilidades desde prácticas e iniciativas alrededor de temas tan sensibles como la memoria, la reconciliación y el perdón.

Este artículo se inscribe dentro de la discusión sobre los conceptos antes mencionados desde las significaciones y experiencias que habilidades como la lectura, la escritura y la oralidad pueden aportar. En cuanto al origen de esta preocupación, vale la pena hacer un breve recuento de la fundación. En el 2016 nace la FILIE, con el objeto principal de generar prácticas de lectura y escritura que permitieran construir una ciudadanía idónea para la democracia. Con esto en mente, en el 2017 creamos una serie de conversatorios que llamamos "Filie en Escena", que tenían como propósito poner en práctica lo que perseguía la fundación. Estos conversatorios giraron alrededor de una pregunta puntual: ¿Cuál es el rol o papel de la lectura, escritura y oralidad en tiempos de posconflicto? De esta manera, con la participación de varias personas que trabajan en distintos campos como la educación, la industria editorial, la memoria histórica y la creación literaria, pudimos articular una visión más precisa y sólida del rol que deberían tener la lectura, la escritura y la oralidad en dicha coyuntura. Entonces, las 
ideas aquí propuestas son la consolidación de nuestros asedios a esa pregunta desde distintos conceptos, experiencias y prácticas.

La lectura, en contra de la concepción común, no es un acto meramente individual sino también social, que involucra a los otros, en lo que se denomina comunidad letrada, donde la lectura es vista ya no solo como una práctica o habilidad, sino, ante todo, como una responsabilidad con la sociedad. De allí que la lectura crítica sea otra de las categorías claves en nuestra investigación, pues conecta lo que cada persona, desde su propio criterio, autónomo y libre, interpreta de la realidad que lo rodea. Sin un ánimo dogmático, pero a la vez sin resignarse frente a su entorno, el lector crítico es un individuo apto para la democracia porque piensa por sí mismo sin considerarse infalible e intocable. Por esto, las narraciones se convierten en una práctica fundamental para generar democracia en un país que poco a poco empieza a desligarse de un pasado excluyente, desigual y violento. Como lo veremos más adelante, las distintas maneras en las que podemos empezar a contarnos como nación son evidencia de nuestra imaginación moral, como lo plantea Jean Paul Lederach, en su libro La imaginación moral. El arte y el alma de la construcción de la paz (2007).

Ahora bien, todas estas maneras de acercarnos a esa pregunta por el rol de la lectura, la escritura y la oralidad en el posconflicto colombiano no podrían dejar a un lado las historias que no solo escritores profesionales han recreado en sus libros, sino también personas que de una manera u otra han sufrido el conflicto armado. Entrever las posibilidades cognitivas, éticas, psicológicas, emocionales, que subyacen en el acto de narrar son también el propósito de nuestras reflexiones que nacieron desde una inquietud que, lejos de ser resuelta de manera concluyente, sí fue enriquecida y, lo mejor, nos llevó a interrogantes y desafíos que la sociedad colombiana de una manera u otra tendrá que afrontar. 


\section{¡CONSTRuyamos Juntos el SENTIDo! En la búsQueda de UnA COMUNIDAD LETRADA}

En una comunidad como la nuestra en la que vamos caminando rodeados de inequidades, ambigüedades, absurdos, vacíos, carencias, las prácticas de la lectura y la escritura son más que necesarias para que no nos ahogue el sinsentido. Precisamente, y como nos lo hace ver la autora argentina Graciela Montes, "Leer es construir sentido. Construir sentido es lo que nos hace humanos, o sea rebeldes" (1999, p. 10). Aunque el enunciado parece evidente, en la práctica, la lectura tiene más obstáculos y enemigos que no permiten que logremos caminar libremente por esa senda. A pesar de que la escuela es el lugar principal con el que asociamos el aprendizaje de la lectura, lo que se ve en un país como Colombia es lo contrario. Desde el ámbito escolar ya se comienza a desmotivar el acto de leer. ¿Cuántos nińos entran a estos espacios académicos enamorados de los libros y salen con un odio profundo y una desmotivación casi inquebrantable? $\mathrm{O}$ en la familia, ¿cuántos miembros consideran importante la lectura y la asumen en sus hábitos diarios sin pensarla solo como un deber académico? Este fenómeno no es solo responsabilidad de la escuela, sino que la familia y las instituciones públicas y políticas también deben asumir su obligación de generar las condiciones para lograr una articulación que nos permita consolidar la lectura en las prácticas culturales de nuestra comunidad.

Aunque en nuestros imaginarios sociales la lectura se comprenda como un acto solitario, la foto de un individuo en un sillón alejado del mundo con un libro en la mano es la representación visual más cercana a esta práctica, la realidad es otra. Leer es un acto político, porque influye y moviliza a la comunidad, desafía e interpela la organización social, y establece diálogos pertinentes y cuestionadores con otros sobre la realidad. Y aquí nos referimos no solo a la lectura de libros, porque como bien dice Montes, "no se lee solo con palabras" (p. 10). Leer es, precisamente, una práctica social y cultural que va modificando la forma como comprendemos el mundo.

Así, el mundo está abierto para ser leído como un gran "libro" de diversos lenguajes. Entonces, es imperativo que su población tenga las herramientas y competencias necesarias para comprenderlo y construir una vida en él. Por tanto, saber leer el contexto vital propio, por ejemplo, el cambio climático, significa comprender las 
señales que la naturaleza pone en evidencia para comportarnos de una manera más amable con el medio ambiente, o poder entender una señal en el lenguaje corporal del otro, que se ha sentido agredido por alguna palabra o acto de nuestra parte, hará que podamos resolver problemáticas con ese otro que vive en nuestro mismo mundo. Así, leer críticamente las noticias se ha vuelto una necesidad, rebelarnos frente a la posverdad ${ }^{1}$ para que seamos nosotros los dueños del destino de nuestro país como un acto de empoderamiento. Este acto podría cambiar la organización política de nuestra nación para que no sean los mismos poderes los que nos gobiernen, porque ellos solo nos han conducido a la violencia.

Como plantea Moisés Wasserman, una verdad, infortunada pero no por ello menos verdad, es que los humanos tenemos grandes dificultades para anular de nuestra conciencia falsedades establecidas por repetición. Reconocemos cosas como si fueran verdaderas mucho después de que ha sido demostrada su falsedad. Hay un fenómeno, conocido hace años en psicología como efecto ilusorio de verdad o efecto de reiteración, por el cual una afirmación se vuelve verdadera para quien la escucha repetidamente, hasta el punto de que el afectado interpreta toda nueva información a la luz de aquella. Es decir, se favorece la reiteración segura sobre el análisis novedoso y arriesgado. Dicho de otra forma, lo más cómodo y frecuente es aceptar como cierto lo que uno ya considera cierto (García Villegas, 2018, p. 62).

Frente a este efecto ilusorio de verdad, la lectura crítica nos permitiría acceder a nuevas formas de ver la realidad. En otras palabras, leer significa construir sentidos más amplios, complejos y diversos que nos permiten vivir decentemente dentro de una comunidad. Conocer y comprender la diversidad, tanto de los lenguajes como de nuestra propia existencia, es un ejemplo de lectura.

Ahora bien, en esa búsqueda de conectarnos con los otros desde la lectura, hemos encontrado que en nuestras comunidades hay más leedores que lectores, siguiendo

1 De acuerdo con el artículo What can philosophy teach as about the post-truth condition del libro Post - truth, fake news (viral modernity and higher education), la posverdad puede ser definida como la distinción que se hace entre hechos y ficción que socavan el terreno moral lo que implica la reconstrucción de la verdad a partir de los hechos. Estas personas se quedan en puros "juegos de lenguaje" donde la ficción y los hechos pierden sus límites indefinidamente (Fuller, 2018). 
al profesor Fernando Vásquez. Nos quedamos en una lectura literal de los acontecimientos. Llegamos apenas a una alfabetización básica de los códigos que configuran los lenguajes. No ponemos en duda aquellos mensajes que recibimos, no establecemos relaciones con otros textos, no revisamos los contextos, simplemente nos quedamos con el significado literal de la palabra o el signo y, por eso, seguimos cayendo como nación en los mismos errores.

La lectura es una actividad; un ejercicio intelectual que sobrepasa la decodificación o el reconocimiento de unas grafías llamadas letras. Leer, por lo mismo, pone a nuestra mente en actitud alerta para formular preguntas, establecer relaciones, rastrear indicios, inferir conclusiones, deducir consecuencias de lo expuesto en un texto. (Vásquez, 2013, p. 79)

Así, tanto la práctica de la lectura, como la de la escritura, tienen relaciones directas con nuestro pensamiento. Ellas configuran nuestra manera de razonar, interpelan diversas competencias intelectuales e imaginativas, cambian nuestras lógicas habituales y expanden nuestras percepciones. Por tanto, para dejar de ser "leedores" hay que convertirnos en intérpretes. Recordemos lo que dice Estanislao Zuleta a propósito de Nietzsche en su famosa conferencia Sobre la lectura: "Al poner el acento sobre la 'interpretación', Nietzsche rechaza toda concepción naturalista o instrumentalista de la lectura: leer no es recibir, consumir, adquirir; leer es trabajar" (1982, p. 4). Precisamente, leer significa trabajar con el texto, hacerle preguntas, intentar comprender por todos los medios qué me quiere decir, generar relaciones con el contexto, establecer puentes entre los significados, etc. En últimas, tomarse el tiempo para pensar. Esto lo demanda cualquier tipo de texto, cualquier tipo de acontecimiento, cualquier lenguaje. Recordemos, entonces, que la realidad es un texto que debe ser interpretado.

Este tiempo de trabajo que nos demanda el pensamiento en el acto lector va en contravía con nuestra forma moderna de vivir. Por eso implica una disposición en todas las dimensiones de lo humano: física, emocional, intelectual y espiritual. El inconveniente, entonces, es que estas disposiciones sean motivadas por todo aquello que nos rodea. Es decir, que esto no solo se enseña en la escuela, o en la familia, sino 
en la red cultural de una sociedad. Por tanto, es importante crear comunidades que se sustenten en estas demandas del pensamiento; lo que llamaremos en este artículo, comunidades letradas:

La escritura y la lectura constituyen dos prácticas decisivas en el desarrollo intelectual y en la formación política de los sujetos. Es un compromiso de la escuela concentrar todas sus fuerzas hacia el acceso y el dominio pleno de esas prácticas que, en general, son un derecho y una vía para cohesionar la ciudadanía y la posibilidad de la democracia. Pero no podemos hablar de lectura y escritura de manera llana, como si entendiéramos con facilidad lo que es saber leer y escribir. Hemos de reconocer que son aprendizajes complejos, que permanecen durante toda la vida, y que no hay una única manera de saber leer y escribir, como lo pretenden los programas de alfabetización que se trazan en nuestros países. Es necesario distinguir entre la escuela que simplemente alfabetiza y la escuela que orienta sus procesos para aprender a leer críticamente los textos que circulan en la vida académica y en la cultura en la que estamos inmersos. (Jurado, 2013, p. 71)

Empezamos por creer que la lectura es un acto solitario, y, si bien implica una soledad necesaria, esto es una verdad a medias. La lectura genera un movimiento pendular entre el individuo y su comunidad. Nadie lee realmente sin ser modificado y su comportamiento demostrará lo leído en la realidad de su contexto. En otras palabras, todo aquel que lee, tarde o temprano, deseará establecer diálogos que construyen conocimiento con otros. La mayoría de los lectores llega naturalmente a la escritura como una forma de crear sentidos propios y comunicarlos a sus semejantes. Va a decir Alberto Manguel, autor de Una historia de la lectura, "todos son lectores y yo tengo en común con ellos sus gestos y su arte, así como la satisfacción, la responsabilidad y el poder que la lectura les proporciona. No estoy solo" (1999, p. 16). Un lector compartirá los beneficios que provee la lectura como motor del pensamiento. Un lector se comunicará constructivamente con otros lectores, y establecerá diálogos que potencian una sociedad. Por este motivo, la lectura no se queda en un soliloquio o un mero acto intimista. Lo requiere, no lo negamos, pero pronto y fuertemente un lector se abrirá a la sociedad y construirá, junto a otros, comunidades letradas enriquecedoras para cualquier nación. 
Por todo lo anterior y en un llamado de esa responsabilidad que impone la lectura, escribimos, narramos y estudiamos esas narrativas que forjan transformaciones profundas en la experiencia humana. Buscamos la configuración de comunidades letradas en nuestro país que muevan el curso cultural de la historia y de la memoria para no quedar anquilosados en una idea obsoleta y estática de lo que somos. La invitación, entonces, es leer, pensar, escribir y actuar en nuestro contexto.

En consecuencia, la lectura de la actual realidad colombiana precisa de lectores críticos que se internen en decodificar el tejido complejo que supone, por ejemplo, unas negociaciones de paz, un periodo de posconflicto con las Farc, la historia de la gobernabilidad en Colombia, los nuevos brotes de violencia y nuestros productos culturales como constructores de imaginarios de estas realidades. Las narrativas en distintos lenguajes tendrán mucho que decir para pensar nuestra coyuntura, pero se necesita que las comunidades a las que van dirigidas sean propiamente lectoras.

\section{LeCTURA CRítica EN EL POSCONFLICTO EN Colombia}

En la actual coyuntura de Colombia entender lo que significa el posconflicto es una posibilidad para sanar las heridas políticas e históricas relacionadas con el conflicto armado. Así pues, no se puede entender el postconflicto como un cese de hostilidades entre dos bandos, un silencio de fusiles donde se establece un ganador y un perdedor. Tampoco puede entenderse como un proceso de reparación de víctimas, ni como de reintegración a la sociedad de los combatientes (Morales, 2015). Todo esto es algo necesario, aunque no es suficiente, ya que no agota los inmensos e importantes desafíos que implica la palabra posconflicto. Más bien, esta coyuntura debería entenderse como una oportunidad de revisar las causas estructurales que llevaron a esta confrontación. De allí que sea preciso distinguir entre conflicto armado y conflicto social; este último, sería cándido e ingenuo suponerlo, no se resolvió en la mesa de negociación de La Habana. Persiste, si nos atenemos a que nuestro país es uno de los países más desiguales del mundo $^{2}$; un país que en su corta vida republicana

2 De acuerdo con el índice Gini, indicador utilizado por el Banco Mundial (вм) para medir la desigualdad en los ingresos económicos, Colombia es el segundo país más inequitativo de América Latina y el séptimo del mundo. 
no ha logrado superar lastres sociales, económicos, políticos y culturales que vienen desde los tiempos de la Colonia.

El posconflicto debería verse como la posibilidad para entender y, a la vez, eliminar esa violencia cultural que permitió la gestación y consolidación del conflicto armado en nuestra sociedad por tantos años. Este término, acuñado por el sociólogo noruego Johan Galtung, plantea que existen unos aspectos de la cultura, que en gran parte son simbólicos y son usados para justificar la violencia directa y estructural contra determinadas personas o agrupaciones (Galtung, 2003). De esta manera, la violencia puede ser aceptada e incluso legitimada, si responde a usos e intereses que están arraigados tanto en la psicología de los ciudadanos como en la institucionalización de las prácticas de una sociedad. De allí que surjan varios interrogantes: ¿cómo los crímenes, o mejor, la violencia puede convertirse en algo aceptable para el grueso de la sociedad? ¿Quién determina cuál violencia es buena o mala? ¿Se puede hablar de muertos buenos y de muertos malos? ¿Se justifica matar en nombre de una idea, de un país, de un proyecto ideológico? Todas estas preguntas que nuestro país debería responderse, o por lo menos intentarlo.

En este sentido, la violencia en nuestro contexto obedece a unas prácticas culturales que han permitido que ciertos crímenes gocen de aceptación por gran parte de la sociedad. Por ejemplo, el expresidente Álvaro Uribe, en su cuenta de Twitter, reenvió un mensaje donde se calificaba a un testigo como "buen muerto" en un caso de vinculación entre Luis Alfredo Ramos y grupos paramilitares. El expresidente, en defensa del exgobernador de Antioquia, sugirió que los muertos en Colombia se clasifican en dos tipos: buenos y malos. Frente a este trino, un sector de la población aprobó sin cuestionar la clasificación, diferenciación y exclusión que implicaba el mensaje.

Este coeficiente se mide en un rango de 0 a 1 , donde cero significa que todos tienen el mismo ingreso y 1 que una sola persona posee todos los ingresos. En Colombia, en las últimas cuatro décadas el coeficiente está en 0,53, a pesar del crecimiento económico que el país ha tenido, incluso en épocas de bonanza petrolera como la de 2006 a 2014 (Serrano, 2018). 
Del mismo modo, el establecimiento colombiano, operando bajo una forma de violencia cultural, durante mucho tiempo logró crear una narrativa en la que unos guerrilleros "delincuentes" y "forajidos", han sido los agresores de un orden y estabilidad. Aquí los términos de violencia estructural y violencia cultural se entrecruzan, ya que el Estado colombiano, al incumplir sus principales deberes con los ciudadanos — violencia estructural—, ha logrado conservar y defender su poder a través de relatos donde se representa como la gobernabilidad, la ley y el orden frente a la ingobernabilidad, la ilegalidad y la anarquía. En consecuencia, esta violencia cultural anula la posibilidad de entender que el conflicto, antes que armado, es social; que existen unas causas estructurales y profundas que han determinado el descontento de un sector de la población, que a través de la violencia directa se ha expresado contra esa violencia estructural que ha encontrado en la violencia cultural el mecanismo ideal para sostener su hegemonía.

No se trata de justificar la violencia directa de grupos insurgentes que nacieron como respuesta frente a la violencia estructural del Estado colombiano, pero sí de comprender las causas que desencadenaron en un conflicto armado. Se trata de entender que el conflicto social degeneró en un conflicto armado, el cual, bajo la forma de la violencia cultural, intentó esconder las profundas inequidades sociales y políticas que sufre gran parte de la población. Ahora bien, ¿̇cómo salir de esta espiral de violencia cultural? Sin ánimo de ofrecer una respuesta única y definitoria, la lectura crítica puede ofrecernos algunos derroteros. A través de esta manera de ver el mundo, los ciudadanos, los lectores que hacen parte de una comunidad letrada como decíamos anteriormente, pueden encontrar los intersticios de esos discursos oficiales que se muestran como una verdad inapelable. Tal como lo plantea el profesor Fabio Jurado, un lector crítico, en últimas, es un lector político, no porque se adhiera a determinada visión política, sino porque es capaz de interactuar con el otro, de reconocer la existencia de distintas posiciones ideológicas desde su propio criterio (2017).

Sin embargo, en una sociedad con tal nivel de desigualdad e injusticia como la nuestra, es casi imposible hablar de una comunidad letrada. No basta con tener una mera opinión, no es suficiente con nacer en un territorio común para sentirnos en una sociedad. Como planteaba el maestro Carlos Gaviria (2015), es necesario construir 
un sujeto para la democracia, de lo contrario, esta palabra pierde todo su sentido y valor. Todo esto nos conduce a esbozar un camino o, por lo menos, unas experiencias que puedan servir como referentes para contar de una manera distinta el conflicto y así construir una paz que sea duradera en medio de las tensiones inherentes que se dan en cualquier sociedad.

Jean Paul Lederach (2007), un referente en mediación y solución de conflictos, propone que la sociedad civil, sin necesidad del Estado, tiene todo el potencial creativo para iniciar y consolidar procesos exitosos de construcción de paz. Lo conocido es la guerra, la confrontación armada para la solución de conflictos; lo que se opondría a esto, según Lederach, sería la imaginación moral. Es una facultad que, a través de la no violencia, la catarsis, los procesos artísticos y creativos, puede llevar a que tengamos otra posibilidad de contarnos, de salir de esa violencia cultural y llegar a una suerte de paz cultural, porque si aceptamos que esta violencia es construida, urdida y manipulada, la paz también puede ser creada, imaginada, real.

Un punto clave de este concepto propuesto por Lederach es que la imaginación moral nace desde las mismas necesidades de la sociedad civil, no por una imposición vertical del Estado. Esta postura se aleja de cualquier pretensión intelectual, pues antes que privilegiar el rol gubernamental de salidas negociadas por parte de los actores en conflicto, acentúa la importancia de las personas que más han sufrido y en general a toda la sociedad civil. En el caso de Colombia, la negociación en La Habana entre las Farc y el Gobierno fue una instancia fundamental, claro está; pero no será suficiente, ya que es necesario que el conjunto de nuestra sociedad proponga nuevos enfoques y alternativas que lleven al camino de la paz. Esta imaginación moral que propone Lederach, en el caso colombiano, está relacionada con la lectura crítica en tanto que un ciudadano, un sujeto verdaderamente preparado para la democracia, puede proponer, crear, generar nuevas maneras de contar el conflicto y así abrir sendas de paz. De allí que la narrativa oficial que dominó la manera de explicar el conflicto armado debe dar paso a nuevas historias más complejas, humanas y existenciales que consoliden una cultura de paz en nuestro territorio. 


\section{LA NARRACIÓN: ENTRE LA MEMORIA Y LA RECONCILIACIÓN}

Para consolidar una cultura de paz es necesario que empecemos a plantear preguntas dentro del ejercicio de narrar historias que estén alejadas de las versiones oficiales de los protagonistas habituales del conflicto armado. Contar lo que ha sido el conflicto desde la visión del establecimiento colombiano supone un sesgo ideológico que habla de unos facinerosos, "bandoleros", que, contagiados por un comunismo importado, propio de las revoluciones de los sesenta y setenta, intentaron tomarse el poder a sangre y fuego. Como decíamos en el apartado anterior, este ha sido el accionar de la violencia cultural desde la versión oficial. A la vez, contar el conflicto desde los grupos guerrilleros supone estrictamente hablar desde un relato en el que existe una élite opresora que continuamente ha despreciado a los sectores más deprimidos y marginados de la sociedad; una historia como resultado de una lucha de clases. Dos narraciones, dos relatos que se han enfrentado en los últimos años de la vida política y social de Colombia, sin posibilidad para otras voces, otros ámbitos, otros puntos de vista. Por ello, es necesario que estas narraciones den paso a otras menos oficiales, menos comprometidas con intereses políticos e ideológicos.

En este punto llegamos a un concepto que en los últimos años se ha hecho cada vez más presente en estas discusiones: la memoria histórica, un concepto que nace luego de la Segunda Guerra Mundial y que surge como una manera de intentar registrar de la forma más fiel los hechos ocurridos luego de estos acontecimientos. El ejercicio de contar las historias cambia, se genera otra perspectiva y dinámica, ya no desde arriba, desde esferas del poder, sino desde abajo, es decir, de aquellos que han sufrido en carne propia los avatares del conflicto: las víctimas. Por supuesto, algunos de los directos implicados en el conflicto dirán que las víctimas pueden ser utilizadas políticamente, pero si nos atenemos a lo que debería ser el genuino papel de la memoria histórica en un conflicto interno como el de nuestro país, esta nos permitiría contestarnos preguntas que la historia oficial ha dejado a un lado.

Por ejemplo, en el caso de los mal llamados "falsos positivos", más allá de las frías estadísticas, de informar lo que fácticamente ocurrió, del deseo natural de encontrar culpables, la memoria histórica nos permitiría preguntarnos: ¿quiénes eran estos muchachos antes de ser asesinados? ¿Cuáles eran sus sueños, sus esperanzas? ¿Qué 
siente un familiar cuándo un ser querido es desaparecido de esta manera? Pero tal vez el desafío más importante que la memoria histórica puede ofrecernos frente a un hecho como este es el de preguntarnos por la posibilidad de construir un relato en el que se responda tanto al pasado como al futuro; esto es, que podamos recordar, pero a la vez abrir la posibilidad de la reparación, del perdón, de la no repetición. Tal como plantea el profesor Peñaranda Supelano al referirse a esa tensión entre pasado y futuro:

\begin{abstract}
¿Cómo será el futuro de nuestro pasado? La responsabilidad de los historiadores está en proponer un relato interpretativo que dé cuenta de la complejidad de los hechos y de sus múltiples manifestaciones. Un relato crítico que albergue una multiplicidad de voces y que mantenga abierta la puerta a una permanente reinterpretación de ese pasado conflictivo, pero a la vez ofrezca a las generaciones futuras una interpretación consistente de los hechos para que el pasado deje de ser esa tragedia permanentemente repetida, ese obstáculo insuperable que bloquea cualquier posibilidad de futuro. (García Villegas, 2018, p. 127)
\end{abstract}

Entonces, si bien la memoria histórica debe contribuir a no olvidar aquellos hechos violentos y dolorosos, tampoco puede caer en un ánimo revanchista, que no permita la construcción de una cultura de paz. Es por eso que, ante un hecho que despierta tanto dolor e indignación como los "falsos positivos", tal vez el mayor interrogante que podemos plantearnos es: ¿̨cómo construir un relato donde la justicia, la verdad y la reconciliación puedan coexistir en medio de las inevitables e inherentes tensiones?

Ahora bien, el dar cabida a contar las historias desde abajo implica que nos preguntemos por las características de la narración, por los procesos de pensamiento que en ella se dan. Lamentablemente, nuestra cultura ha tendido a subvalorar o simplemente olvidar que en la narración se dan cita habilidades complejas de pensamiento que no son solo privilegio del pensamiento lógico. En este sentido, pedagogo Gerardo Andrade, desde el Instituto Alberto Merani ha venido trabajando e investigando sobre lo que pasa en los estudiantes cuando ellos se atreven a contar historias: 
No solo somos sujetos que se adaptan a las realidades. También somos sujetos que adaptan las realidades a su propia realidad. La acción es el motor de la inteligencia que hace que nos adaptemos al mundo; la reflexión es motor de la inteligencia que hace que adaptemos el mundo a nosotros. En el pensamiento narrativo, la reflexión es el hilo conductor de procesos que generan la posibilidad de la narración. Está presente en cada una de ellos como una invariante funcional, para decirlo en términos de Piaget (Andrade, 2017).

La reflexión es ese componente principal al momento de contar historias, de esa exploración que nos lleva a plantearnos lo sucedido a través de operaciones lógicas de pensamiento que son necesarias para vivir, pero que no pueden dar cuenta de la múltiple e incluso infinita gama de sentimientos, emociones, ideas que se esconden detrás de las experiencias humanas. Así pues, al momento de narrar hechos tan dolorosos como los ocurridos en tantos años de conflicto armado, centrarse en la acción, en el pensamiento lógico es insuficiente, pues este solo se concentrará en generalizar, homogeneizar, excluir operaciones que no permiten dar cuenta de la singularidad, lo irrepetible, lo insondable de cada historia humana. En cambio, a través de la narración, de la reflexión como ese proceso central del pensamiento cuando se cuentan historias, podríamos acercarnos más a la comprensión de realidades que parecen no tener sentido o propósito alguno, ya que se parte de la acción, del hecho fáctico que sucede, para llegar a construir historias en las que podemos por lo menos entrever qué es lo que permanece agazapado en las acciones humanas.

De allí que las víctimas, al intentar establecer una comprensión de lo que les ha sucedido, casi que espontáneamente acuden a la narración como una manera de catarsis, de comprensión, de reflexión sobre lo sucedido. Estas pueden ser escritas, orales, acompañadas de otras actividades, mediadas por otras personas, desde otros lenguajes, en diversos soportes. Existen numerosas posibilidades en que la narración puede construirse; lo que importa es que nos atengamos a las condiciones de quién contará esas historias, así como de la recepción que pueden tener. En cuanto a lo primero, en las personas que cuentan las historias, es preciso atenerse a que la escritura no puede ser la única manera de transmitir y guardar esas narraciones, si nos ajustamos al contexto en el que muchas de las víctimas del país se desenvuelven. Muchas de estas personas no han tenido acceso a la educación formal, por lo que sus 
historias tendrán que ser orales o mediadas por alguna persona que pueda llevarlas a la escritura ${ }^{3}$. Esto nos hace pensar en que la narración, más que un producto terminado, consumado, listo para ser publicado, es más un proceso en el que detrás de ella se dan experiencias que en la mayoría de los casos terminan por ser más importantes que el propio acto de la publicación.

Un ejemplo de lo anterior puede ser la experiencia del Centro de Memoria, Paz y Reconciliación que a nivel distrital ha trabajado con varios desmovilizados de distintos grupos - guerrilleros, paramilitares, fuerza pública- y víctimas en talleres de escritura que ha permitido, como plantea Lederach, el encuentro de los improbables, de aquellos jurados enemigos, pero que gracias a la necesidad de contar una historia se reúnen e intentan contar otra, menos sesgada, menos tendenciosa, y más compleja, más incluyente, que tal vez pueda aproximarse a lo que realmente pasó. Como se ve, no importa tanto lo que aparecerá como producto sino lo que se vivió en el proceso de construcción de las historias. Algo que para las víctimas cobra especial énfasis, pues lejos de considerarlas un agente pasivo, la narración, el ejercicio de poder contar historias, hace que adquieran relevancia y protagonismo, que puedan ser parte activa en los hechos dolorosos que han atravesado sus vidas.

La recepción de las historias también es un punto crucial en el que vale la pena detenerse porque muchas veces surgen las preguntas: ¿quiénes serán los que puedan acceder a esas historias? ¿Solo un público especializado, académico, formado? ¿No deberían estas narraciones llegar a toda la ciudadanía? De tal modo, el desafío para las personas e instituciones que trabajan en estos dominios es que se instrumentalice a la víctima. Que esta se convierta en un pretexto para un estudio, para un ensayo, para nuestro artículo como en el presente caso, pero que a la vez se olviden de sus reclamos, de sus intereses, de sus narraciones. La literatura es insuficiente, el testimonio de personalidades que han sufrido calvarios tampoco es suficiente; aseguran un público, pero no llegan a otros que han sufrido marginalidad, que no tienen acceso a estos

3 Estas historias también se expresan por otros medios como la fotografía, las artes plásticas, el teatro. Un ejemplo de esto es la exposición permanente del Centro de Memoria, Paz y Reconciliación, denominada Recordar: volver a pasar por el corazón, en la que los asistentes podrán recordar esos hechos, personajes, historias, objetos, lugares, que el conflicto armado dejó en Bogotá; todo, a partir de una apuesta directa y cálida con el espectador, pues en la exposición se articulan distintos lenguajes como el audiovisual, el fotográfico y, claro está, el lingüístico. 
productos culturales. De allí que entonces se hable de instrumentalizar a la víctima porque se le toma como excusa para articular algunas historias que pueden ser vendidas. Por esto, es necesaria la reinvención de nuevas formas de contar historias para que lleguen a otros públicos, a otros rostros.

¿Cómo asegurar entonces que las historias contadas puedan tener un real y verdadero impacto en la ciudadanía? La respuesta a este interrogante no puede ser otra que la creación y la consolidación de una genuina comunidad letrada que asegure un sólido tejido social y cultural en el que las personas puedan construirse a sí mismas desde el reconocimiento de los otros, de su dignidad, de su valor como personas con derechos. Para ello, es necesario superar varios lugares comunes alrededor de la lectura y la escritura. El primero de ellos tiene que ver con que solamente exista un dominio estricto del código escrito, cuando cada vez es más evidente que la oralidad y otras expresiones artísticas son medios válidos y perfectamente idóneos para contar historias. Otra concepción arraigada que está en relación con la anterior es que el acto de leer sea individual y solitario, cuando en realidad supone un entramado de relaciones y experiencias humanas, tal como planteábamos en la primera parte de este artículo.

Así, al reconocernos en una comunidad letrada podríamos reconstruir el tejido social de un país que se ha negado por mucho tiempo la construcción de una sociedad. Y qué mejor para ello que las historias de las distintas personas que han estado presentes en la construcción de esta sociedad; desde el Estado, la Iglesia, los militares, la guerrilla, los paramilitares, las víctimas, la ciudadanía en general, todas podrían construir un gran relato nacional, no necesariamente homogéneo y monótono; al contrario, tendría que ser vibrante y conflictivo. Tal vez así podamos construir un relato que, si bien nace desde abajo, tal como decíamos anteriormente que nació la memoria histórica, debe intentar tener en cuenta a todos los actores y factores que estuvieron presentes durante el conflicto armado. Porque no es viable optar por el olvido que borra de nuestro horizonte la verdad que ha estado escondida durante mucho tiempo en tantos ańos de guerra, pero tampoco podemos limitarnos a la condena de los "culpables", de vivir en el rencor, motor útil de la venganza. El compromiso de las historias es tanto con la memoria como con la reconciliación. 


\section{COLOMBIA, UN PAÍS PARA SER COMPRENDIDO DESDE MÚLTIPLES NARRATIVAS}

Al reconocer el potencial político y cultural que las formas narrativas poseen, podemos ver cómo la realidad va tomando cuerpo en esa red de complejidades que la constituyen, puesto que comienzan a surgir diferentes temas, voces y puntos de vista que son parte fundamental de nuestra realidad. Es decir que no nos quedamos con una sola historia para comprender nuestros contextos, siguiendo la propuesta de la autora nigeriana Chimamanda Adichie (2009). No nos quedamos con la narrativa oficial de ciertos medios de comunicación sobre el conflicto armado, las migraciones, el desplazamiento o la desigualdad, sino que a partir de diferentes productos culturales podemos acceder a nuevas formas de leer esas problemáticas sociales y sus efectos.

Nuestra realidad es compleja, variopinta y desbordada. Nuestra realidad es un lienzo pintado con múltiples colores. Como decía Gabriel García Márquez en su discurso al recibir el Premio Nobel de Literatura:

Una realidad que no es la del papel, sino que vive con nosotros y determina cada instante de nuestras incontables muertes cotidianas, y que sustenta un manantial de creación insaciable, pleno de desdicha y de belleza, del cual éste colombiano errante y nostálgico no es más que una cifra más señalada por la suerte. Poetas y mendigos, músicos y profetas, guerreros y malandrines, todas las criaturas de aquella realidad desaforada hemos tenido que pedirle muy poco a la imaginación, porque el desafío mayor para nosotros ha sido la insuficiencia de los recursos convencionales para hacer creíble nuestra vida. Este es, amigos, el nudo de nuestra soledad. (García Márquez, 1982, párr. 6)

Hacer creíble nuestras realidades es un desafío de los escritores, de los artistas, de los narradores, porque para un extranjero, sucesos que acontecen en el día a día de las personas de nuestro país son actos de la imaginación y no productos de la realidad desbordada en la que estamos inmersos. Es necesario hacer comprensible nuestra realidad para los foráneos, pero sobre todo para nosotros mismos, ya que evidentemente ha desbordado nuestra capacidad de comprensión; es un reto para 
el creativo, para la escritura, para el arte. Poder hacer una mirada compleja y no reduccionista es todo un desafío para los intérpretes.

Nuestra realidad histórica y cultural está ahí para ser leída y pensada, pero no desde los mismos mecanismos y desde las mismas orillas; esta nos reclama que deshagamos el nudo de la soledad que plantea García Márquez. Tenemos que leerla en clave de la diversidad, de forma comunitaria, en diálogo con los contextos que están más distantes. Ya no nos sirve una mera alfabetización homogeneizante para jactarnos de decir que somos lectores del mundo. Necesitamos tener oídos para escuchar lo más sutil del alma de nuestras comunidades, aquello que ha sido banalizado con puras estadísticas. En últimas, es necesario permitirle aparecer al otro en su completa diferencia y acogerlo. Ese otro que también somos nosotros mismos y con quien podemos dialogar siempre y cuando nos permitamos leerlo. Seguimos las ideas de María Teresa Andruetto en su libro La lectura, otra revolución:

La dificultad de incluir a otros diferentes de nosotros parece haber sido una constante en nuestra historia, pero tal vez también en las historias de otros pueblos. De haber escuchado, de haber prestado atención a lo que oíamos, de haber vuelto los ojos hacia lo que permanecía excluido, olvidado o negado, también hubiéramos podido comprender y ser comprendidos, además de volvernos más responsables. La pregunta que habilita una escucha tiene estatura ética porque le da cabida al otro, nos permite alojar su humanidad, hacerle un lugar en ese relato de todos. (Andruetto, 2014, p. 109)

En este punto, es preciso recordar el poder que tiene la literatura de acercarnos a aquello que está más distante o que hemos olvidado. Un poder que no ha sido visibilizado ni comprendido del todo, porque, para algunos, es un mero divertimento y, para otros, algo que está más allá de nuestro entendimiento cotidiano. La literatura permite adentrarnos en realidades lejanas y nos hace sentir como si fuéramos partícipes de ellas. ¿Acaso esto no se parece al adagio popular que invita a ponerse en los zapatos del otro? ¿Acaso no parecíamos ser nosotros los que recorríamos las estepas rusas mientras leíamos Miguel Strogoff, desde acá en el trópico y, sin embargo, allá en los montes Urales entendíamos el dolor del mensajero Siberiano? La literatura, si de algo sirve, 
es para generar oportunidades en las que los lectores podamos convertirnos en seres más solidarios. Así, simular la realidad deja de ser un mero mecanismo artificioso de la escritura literaria: se convierte en una oportunidad política de permitirle al otro que exista.

En esa diversidad de narrativas, entonces, y a modo de ejemplo de lo que hemos venido desarrollando en este artículo, presentaremos algunas obras literarias, cinematográficas y algunos espacios didácticos que desde nuestra experiencia han permitido lecturas propias, diversas, catárticas y propositivas que enriquecen nuestra forma de comprendernos y de expresarnos. Estos ejemplos no constituyen una totalidad representativa, ni una antología de los productos creativos de nuestro país; tan solo ilustran un recorrido desde la experiencia, pero que logran ser reveladores para la reflexión que llevamos en este texto. Así, como dice Juan Gabriel Vásquez: "Necesitamos historias: estamos programados para vivir en ellas, para entendernos a través de ellas, para imaginar al otro, a través de ellas. Entre el vacío y una historia mentirosa, preferimos la historia mentirosa” (García Villegas, 2018, p. 138).

\section{La dignidad de la palabra y la imagen}

Con la obra de Jairo Buitrago, escritor colombiano de libro álbum ${ }^{4}$, Camino a casa, la narrativa es contada desde la palabra y la imagen. La ilustración dice tanto como las palabras del relato y, en una sola imagen, nos sugiere un contexto que ha sido poco visibilizado en otros discursos. Un contexto enmarcado en nuestras ciudades, sus problemáticas sociales y la dignidad de una niña de bajos recursos que vive en la periferia y debe volver a casa sola. Este es el motor de una narrativa potente que nos hace solidarios con aquellos que viven estas condiciones.

4 Para la historia de la literatura infantil, el libro-álbum es un género muy importante que surge en la primera mitad del siglo xx. "Este género, propio de la literatura infantil, se basa en el principio de que la ilustración y el texto deben hacer parte de un todo narrativo, fusionando en muchos casos el papel del ilustrador y el del autor. La estructura secuencial de sus páginas, el ritmo y la preponderancia de las imágenes desempeńan un papel fundamental. Además, el libro-álbum tiene un cariz lúdico de experimentación artística que se deriva del ingenio de su contenido; de ahí proviene su ubicación como producto cultural emblemático de la posmodernidad." (Pardo, 2009) 
Desde la primera imagen se nos muestra las huellas de una pequeña junto a las de un león que es su fiel acompañante, un animal que simboliza tantos valores que apreciamos. Este último puede ser leído de muchas maneras; sin embargo, es un claro símbolo de valentía y coraje de esa pequeña que es hija de su contexto social, económico y político. ¿Cuántos niños en Colombia comparten estas realidades que muestra bellamente Buitrago en un simple libro para niños? ¿Cuántas personas se solidarizan con este personaje tan solo al mirar las ilustraciones?

Un león que leído de forma literal es tan solo un elemento de la fantasía del escritor, pero que leído de manera interpretativa, se convierte en un potente símbolo de dignidad. Comprendemos la complejidad simbólica que esa imaginación está proponiendo como lectura de una realidad que interpela a ser descifrada. Una niña que se recorre media ciudad para recoger a su hermano de brazos, hacer las compras como toda una adulta y saber que no tiene dinero suficiente, que debe subirse en dos ladrillos para alcanzar la estufa y poner la sopa, porque su madre trabaja en una fábrica y no puede ocuparse de ellos, una ańoranza del padre y una vida que sigue. Esta realidad es mostrada estéticamente y se le provee de un estatus distinto al del mero lloriqueo victimizante de algunos discursos mediáticos. Nos permite reconocer que nuestros contextos son disímiles, pero que podemos comprenderlos y conectarnos de manera más humana.

Se ha creído vagamente que la obra de Jairo Buitrago es una obra para público infantil; sin embargo y aunque los niños disfruten y aprendan de su literatura, su obra nos permite leer las realidades en cualquier franja de edad. No se reduce a un mero divertimento para el público infantil, sino que provee las oportunidades de interpretar de maneras distintas las otras facetas de la realidad por más duras que sean. Otro ejemplo de esto es su obra Eloisa y los bichos. En esta propone lo que significa vivir como migrante. Allí, genera una oportunidad de acercarnos al problema actual contemporáneo de las migraciones, a nuestros semejantes venezolanos que piden refugio en nuestros límites territoriales, a nuestros campesinos, que deben dejar su tierra debido a la violencia, o a aquellos que, por diversas razones, deben abandonar lo que conocen para arriesgarse a construir una vida en un contexto desconocido. 


\section{La catarsis y el extrañamiento de un conflicto de más de cincuenta años}

Cada vez que leemos en comunidad la obra de Evelio José Rosero, Los ejércitos, se genera una especie de catarsis colectiva en la que comienza a significar, con una sensibilidad particular, el conflicto que ha azotado a miles y millones de personas en este país. Las innumerables noticias sobre el conflicto armado en Colombia no han causado un efecto sensible en las personas, sino que la muerte se ha reducido a una simple cifra distante y fría. En este caso, la literatura, entonces, genera un cambio de disposición afectiva en la que el lector se conmueve y se extraña de una realidad que para nosotros ha sido naturalizada desde hace bastante tiempo. Con esta obra ficcional, pero que está soportada por sucesos que ocurrieron en distintos pueblos del campo colombiano, tenemos una oportunidad como país de comprender las distancias geográficas, territoriales, ideológicas y culturales entre el campo y la ciudad.

En esta misma línea, y cuando hemos puesto a dialogar a estudiantes que vienen de diversas regiones con esta obra, surgen inmediatamente las experiencias e historias de vida de cada uno, que se identifica analógicamente a lo que propone el autor en Los ejércitos. Uno a uno, los participantes de esta lectura colectiva tienen algo que decir desde su lugar de enunciación, lo que permite ampliar la comprensión no solo de la obra literaria como tal sino del conflicto armado en Colombia y sus implicaciones. Hacemos de este relato una narración colectiva que nos conecta y nos hace partícipes de la comunidad. Esta comprensión ampliada de lo que nos corresponde como habitantes de este país se debe a lo que anteriormente llamamos comunidad letrada.

\section{La búsqueda de un lugar en el mundo para todos}

Una invitación a escuchar las historias de aquellos que han sido marginados por nuestra sociedad es la película Señorita María: la falda de la montaña (2017), del director colombiano Rubén Mendoza. Esta producción permite visibilizar esa lucha entre lo que somos y lo que otros esperan que seamos. Un relato que logra conmover y darles una vuelta a los imaginarios sociales para demostrar que con obstáculos y dificultades todos estamos buscando pertenecer a un lugar en este mundo. Este riesgo que asume el director de contar lo que no se ha contado es una forma de darle lugar 
y voz a esos personajes ocultos que siguen siendo parte de nuestras sociedades y que como tal se les debe permitir su existencia.

Así, este documental presenta a un hombre que se siente mujer y que vive en un pueblo de tradiciones conservadoras. Un personaje que habita de manera humilde un territorio y debe enfrentar condiciones rurales marcadas por un olvido del Estado, de aquella institucionalidad que debería trabajar por permitirnos a todos (no importa la raza, el género, el credo, la condición social, etc.) un lugar para vivir dignamente. ¿Por qué tanta resistencia a la diferencia? ¿Acaso todos no somos diferentes y, sin embargo, podemos establecer puentes para que nos una lo que tenemos en común?

Existe la dificultad en establecerse como parte integral de esa sociedad, siendo lo que la señorita María es. Sin embargo, contar su historia es una manera de resistir y hacer respetar la forma en la que ha decidido habitar el territorio. Y aunque esta manera siga siendo para algunos inaceptable, el testimonio encarnado en esta producción cinematográfica nos siembra la posibilidad de ampliar nuestra visión de mundo de lo que las tradiciones y los prejuicios sociales instauran.

\section{Otras voces, otros escuchas}

En la Feria del Libro de Bogotá del 2018, el Centro Nacional de Memoria Histórica propuso en su estand una narrativa original para crear memoria sobre el conflicto armado en Colombia. La creatividad estaba dada en el punto de vista de los narradores, en este caso, los tres ejes temáticos que eran la tierra, el agua y el cuerpo. Por primera vez se logró escuchar a la tierra hablar, desde su propia perspectiva, sobre las implicaciones del conflicto que ha atravesado por tantos territorios y comunidades. Esta propuesta fue una muestra de cambio en las formas de relatar nuestra historia y, por tanto, darles lugar a nuevos significados. Un tema como el del medio ambiente, que a primera vista parece alejado de la comprensión de la violencia en Colombia, se puso en la mesa de los espectadores para ser reflexionado en su complejidad. La tierra tiene tanto que decirnos sobre estos temas que, en esta oportunidad, pudimos escuchar. Lo mismo sucedió con el agua y con el cuerpo. Este último permitía que nos acercáramos por un momento a las historias de vida de lo 
que significan los cuerpos violentados. Cuerpos que, por no concebirse de manera habitual, fueron sometidos, cuerpos que fueron usados como conquista del poder y el dominio de un grupo armado. Por consiguiente, y gracias a esta forma didáctica de presentar la memoria, se nos dio la oportunidad de escuchar lo que jamás creímos que pudiera hablar con tanta fuerza sobre el conflicto.

\section{Conclusiones}

Como hemos desarrollado a lo largo de este artículo, creemos en el desafío y la necesidad de construir comunidades letradas que desarrollen la lectura critica para generar cambios en nuestros sistemas simbólicos y, con ellos, en nuestra cultura; cambios en la forma como nos relacionamos con otros y como vemos la realidad. Creemos en una comunidad que motive las disposiciones afectivas e intelectuales que exigen las prácticas lectoras y que nos transformemos en una ciudadanía participativa. Para este fin, configuramos prácticas de lectura, escritura y oralidad que fomentamos desde la FILIE para construir sentidos amplios, complejos y diversos sobre lo que ha sucedido en el contexto del posconflicto. Intentamos escuchar las voces que han sido silenciadas a lo largo de nuestra historia y que, desde la literatura, el arte y las manifestaciones culturales en general, se oponen a la violencia simbólica de la que hemos sido víctimas. Así, nuestro aporte se centra principalmente en este desafío, y aunque conocemos los obstáculos y dificultades para crear estas comunidades, no nos acalla la resignación, sino que la realidad del país nos motiva a seguir generando espacios para la reflexión como lo es este texto.

En cuanto al impacto que tuvo el conflicto armado en nuestro país, una de las más graves consecuencias fue la normalización de la violencia, un fenómeno que puede ser explicado por los mecanismos de la violencia cultural. Sin embargo, para gran parte de la población colombiana la violencia obedece a aspectos biológicos, a una condición inscrita en nuestra genética que explica nuestro carácter violento y que, por ende, estamos condenados irremediablemente a vivir en una sociedad donde siempre va a imperar la ley del más fuerte, de los violentos que pueden intimidar bien sea con un arma, un símbolo o el silencio. Ahora bien, una forma de evitar caer 
en este fatalismo, en este pesimismo tan rudimentario como ingenuo, es empezar a preguntarnos, y de esta manera comprender, cuáles fueron las causas, las raíces que aún permanecen para que se desataran tantos años de conflicto armado. Esto no implica desconocer la realidad de que somos un país particularmente violento, sino a tener una visión más compleja, profunda y holística de un fenómeno que es a la vez imposible de reducir a una sola variable. No ha sido la intención de nuestro artículo examinar cuáles han sido las causas de esa violencia, pero sí de analizar cuál ha sido esa lógica a partir de la cual los principales actores del conflicto actuaron y formularon narrativas que les han permitido legitimar sus acciones.

Para ello, como nos enseñaba Baruch Spinoza, no hay que reír ni llorar sino comprender. Y una herramienta que nos permite comprender lo que ha sucedido en tantos años de confrontación es la lectura crítica, una habilidad que en nuestro país dista de ser algo habitual y cotidiano, pero que no por esto deja de ser necesaria. Sin asumir una postura ideológica o partidista, la ciudadanía gracias a la lectura crítica refina su cultura política al estar más preparada para los desafíos de la democracia. Esta es una palabra problemática, pues ha perdido su sentido original y ahora parece no significar nada. Desde distintas orillas la invocan, aseguran representarla, poseerla, sin que sepamos muy bien a qué se están refiriendo. Por eso, Estanislao Zuleta, consciente de la instrumentalización en la que ha caído la democracia, advertía que la lucha, más que contra un adversario u oponente, es contra nosotros mismos, si queremos ser llamados democráticos, pues la tendencia que tenemos es a desentendernos de lo que implica tomar decisiones y de la dificultad de pensar por nuestra propia cuenta (Zuleta, 2016). A esta dimensión de la democracia no se le ha prestado suficiente atención porque implica una revisión de nosotros mismos, una mirada casi que psicoanalítica, la cual pocos estarían dispuestos a enfrentar; sin embargo, debemos hacerlo. Ser democráticos no es una tarea fácil: nuestro instinto apunta a lo totalitario, a lo autocomplaciente, a lo que es conveniente a nuestros deseos, pensamientos y opiniones.

Para esa tarea de no ceder a los impulsos que nos llevan a ser antidemocráticos por esencia o por naturaleza, la memoria histórica cumple un rol determinante. Esta tiene una misión compleja pues atiende al pasado, el presente y el futuro. Al pasado, en tanto nos recuerda lo sucedido, por terrible y espantoso que haya sido; al presente 
porque ese pasado se construye con personas e historias del presente; al futuro, ya que una de las principales funciones de la memoria es la no repetición de esos hechos violentos que tanto degradaron a los actores del conflicto. De este modo, la memoria es tanto sincrónica como diacrónica, tiene una mirada tanto retrospectiva de los hechos como prospectiva. En esa dialéctica temporal es imposible sustraerse y una noción como el perdón encuentra su sentido. En efecto, al escuchar a varias de las víctimas, muchas de ellas hablan de que son capaces de perdonar, pero nunca de olvidar; es un perdón sin olvido, un mantra que parece repetirse en varios de los testimonios de las víctimas. Un perdón que recuerda (pasado), que se reconstruye en el hoy (presente) y que posa su mirada hacia adelante (futuro).

\section{REFERENCIAS}

Adichie, C. (2009, julio). El peligro de la historia única. [archivo de video]. Consultado en https://www.ted.com/talks/chimamanda_ngozi_adichie_the_danger_of_a_single_ story?language $=\mathrm{es} \# \mathrm{t}-5565$.

Andrade, G. (2017, junio). Pensamiento narrativo y escritura para la comprensión humana. En A. Saénz (presidente), III Encuentro FILIE en Escena. Fundación Itinerarios de Lectura y Escritura (FILIE).

Andrueto, M. T. (2014). La lectura, otra revolución. México D. F.: Fondo de Cultura Económica.

Buitrago, J. y Yockteng R. (2008). Camino a casa. Ciudad de México: Fondo de Cultura Económica.

Buitrago, J. y Yockteng R. (2009). Eloisa y los bichos. Bogotá: Babel Libros.

Fuller, Steve. (2018). What can philosophy teach about us about the post-truth condition. En M. A. Peters, S. Rider, M. Hyvönen, T. Besley (eds.), Post-Truth, Fake News: Viral Modernity \& Higher Education (pp. 13-26). Singapore: Springer. 
Galtung, J. (2003). Violencia Cultural. Biskaia: Red Gernika.

García Márquez, G. (1982,). La soledad de América Latina. Discurso de aceptación del Premio Nobel de Literatura, Estocolmo. Consultado en https://bit.ly/2RW7g10.

García Villegas, M. (ed.). (2018). ¿Cómo mejorar a Colombia? 25 ideas para reparar el futuro. Bogotá: Ariel.

Gaviria, C. (2015). ¿Cómo educar para la democracia? [archivo de video]. Gimnasio Moderno. Consultado en https://bit.ly/3aQWule.

Jurado, F. (2009). La evaluación de la escritura para la evaluación de la lectura. Revista Iberoamericana de Evaluación Educativa, 2(1), 131-146. Consultado en https://bit. ly/38O7gHe.

Jurado, F. (2017, junio). Comunidad letrada. En A. Saénz (presidente), I Encuentro FILIE en Escena, organizado por la Fundación Itinerarios de Lectura y Escritura (FILIE). Bogotá, Colombia.

Lederach, J. P. (2007). La imaginación moral. El arte y el alma de la construcción de la paz. Bilbao: Bakeaz.

Manguel, A. (1999). Una historia de la lectura. Bogotá: Editorial Norma.

Mendoza, R. (director). (2017). Señorita María: la falda de la montaña [documental]. Colombia: Rubén Mendoza.

Montes, G. (1999). De lo que sucedió cuando la lengua emigró de la boca. Lectura y vida. Revista Latinoamericana de Lectura, (3), 2-10.

Morales Nieto, J. (2015). ¿Qué es el Postconflicto? Colombia después de la guerra. Bogotá: Penguin Random House. 
Pardo, Z. (2009). Panorama histórico del libro ilustrado y el libro-álbum en la literatura infantil colombiana. Ensayos. Historia y teoría el arte, (16), 81-114.

Rosero, E. (2007). Los ejércitos. México D. F.: Tusquets editores.

Serrano, M. (2018, 23 de enero). Pese al crecimiento económico, Colombia sigue siendo uno de los países más inequitativos del mundo. uN Periódico digital. Consultado en https:// unperiodico.unal.edu.co/pages/detail/pese-al-crecimiento-economico-colombia-siguesiendo-uno-de-los-paises-mas-inequitativos-del-mundo/.

Vásquez, F. (2013). De lectores, leedores y otras consideraciones sobre las prácticas de lectura en la educación superior. Revista de la Universidad de la Salle, (62), 77-91.

Zuleta, E. (1982). Sobre la lectura. Consultado en http://www.ram-wan.net/restrepo/metodologia/zuleta_sobre\%20la\%20lectura.pdf.

Zuleta, E. (2016). Educación y democracia. Bogotá: Editorial Planeta. 